\title{
Structural Analysis of Molten Fe-Si Alloys by X-ray Diffraction*
}

\author{
By Yoshifumi KITA,** Masafumi ZEZE*** and Zen-ichiro MORIT ${ }^{* *}$
}

\begin{abstract}
Synopsis
Detailed measurements of $X$-ray diffraction on molten $\mathrm{Fe}-\mathrm{Si}$ alloy, one of the fundamental systems in iron- and steelmaking, have been carried out over the whole concentration range at about 10 at $\%$ Si intervals at temperatures $50^{\circ} \mathrm{C}$ above the liquidus.

The total interference functions $a(K)$ and the radial distribution functions $4 \pi r^{2} \rho_{0} g(r)$ were estimated, from which the position $K_{1}$, the height $a\left(K_{1}\right)$ and the half width $W$ of the first peak of $a(K)$, and the nearest neighbour distance $r_{1}$ and the coordination number $n_{1}$ were also obtained. The partial interference functions $a_{\mathrm{FeFe}}(K)$ and $a_{\mathrm{SiSi}}(K)$ were estimated at 30 at $\%$ Si by a concentration method.

It was found that in the concentration range up to 40 at $\% \mathrm{Si}$, the overall feature of $a(K)$ and $g(r)$, together with $K_{1}, a\left(K_{1}\right), W, r_{1}$ and $n_{1}$ is almost similar to that of molten $\mathrm{Fe}$. While for the alloys in the concentration range beyond 50 at $\% \mathrm{Si}$, with increasing $\mathrm{Si}$ content, the first peak of $a(\kappa)$ becomes broader and more asymmetric, the first peak of $g(r)$ becomes narrower and the subsequent peaks are more strongly damped, and $n_{1}$ decreases.

From these facts, it was deduced that the structure of molten $\mathrm{Fe}-\mathrm{Si}$ alloys is nearly close-packed in the range up to 40 at $\% \mathrm{Si}$, and then gradually changes to be more open, lower-coordinated with increasing Si concentration. The comparison of these results with other properties closely related to the liquid structure was also made.
\end{abstract}

\section{Introduction}

From the standpoint of iron- and steelmaking, especially in relation to properties of melts, it is important and interesting to obtain precise information on the atomic structure of molten Fe-based alloys. As is well known, in molten Fe-Si alloy, which is one of the fundamental systems in iron- and steelmaking, thermodynamic activities of $\mathrm{Fe}$ and $\mathrm{Si}$ show a remarkable negative deviation from Raoult's law, ${ }^{1)}$ thus representing a strong interaction between $\mathrm{Fe}$ and $\mathrm{Si}$ atoms. Therefore, interest has been focused on the structure as well as various properties of this alloy system recently.

Formerly at the Fourth Japan-USSR Joint Symposium in 1973, Vatolin and Pastuhov' ${ }^{2)}$ presented an $\mathrm{X}$-ray study on the structure of molten alloys of $\mathrm{Fe}$ and $\mathrm{Ni}$ with $\mathrm{Si}$ and $\mathrm{C}$, in which they suggested that experimental results on molten $\mathrm{Fe}-\mathrm{Si}$ alloys can be explained by a structure model based on crystalline $\mathrm{FeSi}, \mathrm{FeSi}_{2}, \mathrm{Fe}$ and $\mathrm{Si}$, and on quasi-eutectic versions.

On the other hand, more recently, Waseda and Tamaki, ${ }^{3)}$ and Waseda and Shiraishi ${ }^{4)}$ carried out Xray diffraction analysis for molten $\mathrm{Fe}-\mathrm{Si}$ alloys, and obtained three partial interference functions $a_{\mathrm{FeFe}}(K)$, $a_{\mathrm{FeSi}}(K)$ and $a_{\mathrm{SiSi}}(K)$, using an anomalous scattering technique. In their results, it was shown that the partial interference functions were nearly independent of the concentration of alloys, and that the $\mathrm{Fe}$ and $\mathrm{Si}$ atoms act, to the first approximation, as hard spheres in molten $\mathrm{Fe}-\mathrm{Si}$ alloys.

Since both of X-ray diffraction studies quoted above had given results rather conflicting each other, it is considered that a study on the structure of molten $\mathrm{Fe}-\mathrm{Si}$ alloys is still to be performed in detail and precisely, taking special care of the problem how the structure of these alloys changes with composition. In this study, from the above standpoint, the structure of molten $\mathrm{Fe}-\mathrm{Si}$ alloys has been investigated in detail by X-ray diffraction over the whole concentration range at various compositions.

\section{Experimental}

The X-ray diffraction was carried out using a $\theta-\theta$ diffractometer which is similar to that previously used. ${ }^{5)}$ The X-rays radiated from a Mo target and passed through a divergence slit ( $1 / 6$ or $1 \mathrm{deg}$ ), were reflected from the free surface of the molten specimen. The scattered X-rays were then monochromatised by a curved graphite crystal after passing through a scattering slit (1 or $2 \mathrm{deg}$ ) and a receiving slit $(0.6 \mathrm{~mm}$ wide), and finally counted by a scintillation counter. In order to collect the scattered X-rays more effectively, divergence and scattering slits were replaced by wider ones ( 1 and $2 \mathrm{deg}$, respectively) for scattering angles higher than about $\theta=15 \mathrm{deg}$.

The scattering intensities were measured over the angular range, from $\theta=3 \mathrm{deg}$ to $\theta=42 \mathrm{deg}$, with the step-scan mode at intervals of $0.25 \mathrm{deg}$ over the first peak and at $0.5 \sim 2 \mathrm{deg}$ intervals for the remaining part. The complete intensity curve was obtained from the scan of three times or more, finally accumulating more than $3 \times 10^{4}$ counts at each scattering angle, and the probable error of the mean curve was $\pm 2 \%$ including a statistical error and an unavoidable error resulting from experimental conditions.

The specimens were heated by a Mo heater, melted in an alumina cell (meniscus area, $25 \times 35 \mathrm{~mm}$ ) in a purified $\mathrm{Ar}-10 \% \mathrm{H}_{2}$ atmosphere, and held at the given temperature with an accuracy of $\pm 5{ }^{\circ} \mathrm{C}$. The alloy specimens were prepared from high-purity $\mathrm{Fe}$ $(99.98 \%)$ and $\mathrm{Si}(99.999 \%)$.

In this study, measurements were carried out on molten $\mathrm{Fe}-\mathrm{Si}$ alloys for the whole concentration range at intervals of about 10 at $\% \mathrm{Si}$, at temperatures about $50{ }^{\circ} \mathrm{C}$ above the liquidus. The compositions of the specimens and their temperatures at which measure-

* Based on the paper presented to The Eighth Japan-USSR Joint Symposium on Physical Chemistry of Metallurgical Processes, June, 1981, ISIJ, Tokyo, (1981), in English. Manuscript received March 31, 1981. (C) 1982 ISIJ

** Department of Metallurgical Engineering, Faculty of Engineering, Osaka University, Yamadaoka, Suita 565.

*** Graduate School, Osaka University. 
ments were made are indicated in Fig. 1 by solid dots on the phase diagram of the $\mathrm{Fe}-\mathrm{Si}$ system. ${ }^{1}$ )

\section{Analysis of Intensity Patterns}

Although the method of analising the observed Xray intensity is familiar in this field, ${ }^{6)}$ a brief description is given below for the convenience of discussion.

The scattering intensity was at first corrected for background counts and for polarization effect ${ }^{7)}$ occurring at both the molten specimen surface and the monochromator, then normalised to absolute units by two methods, i.e., high angle method ${ }^{7)}$ and KroghMoe Norman method, ${ }^{8,9)}$ using atomic scattering factors for $\mathrm{Fe}$ and $\mathrm{Si}$ calculated by Cromer and Waber ${ }^{10}$ ) with a correction for the anomalous dispersion. ${ }^{11)}$ In this procedure, a correction for the incoherent scattering ${ }^{12,13)}$ was also taken into account.

The total interference function $a(K)$ was obtained from the resulting intensity of the coherent scattering per atom in electron units, $I_{\mathrm{eu}}^{\mathrm{coh}}(K)$, and expressed for a binary system as follows:

$$
a(K)=\left\{I_{\mathrm{eu}}^{\mathrm{coh}}(K)-\left\langle f^{2}\right\rangle+\langle f\rangle^{2}\right\} /\langle f\rangle^{2}
$$

where, $K=4 \pi \sin \theta / \lambda ; \quad 2 \theta$ : the scattering angle,

$\lambda$ : the wave length

$$
\begin{aligned}
\left\langle f^{2}\right\rangle & =c_{i} f_{i}^{2}+c_{j} f_{j}^{2} \\
\langle f\rangle & =c_{i} f_{i}+c_{j} f_{j}
\end{aligned}
$$

$c, f:$ atomic concentration and atomic scattering factor with $i$ and $j$ referred to atomic species.

The partial interference functions required to characterise a binary system $a_{i i}(K), a_{j j}(K)$ and $a_{i j}(K)$ were calculated by means of a concentration method ${ }^{14)}$ using $a(K)$ at three different concentrations over a limited range where the partial structure was assumed to be invariant, according to a generalised relationship:

$$
\begin{aligned}
a(K)= & \left\{c_{i}^{2} f_{i}^{2} a_{i i}(K)+c_{j}^{2} f_{j}^{2} a_{j j}(K)\right. \\
& \left.+2 c_{i} c_{j} f_{i} f_{j} a_{i j}(K)\right\} /\langle f\rangle^{2}
\end{aligned}
$$

The atomic radial distribution function (RDF) $4 \pi r^{2} \rho_{0} g(r)$ was evaluated by the Fourier transformation of the interference function:

$$
4 \pi r^{2} \rho_{0} g(r)=4 \pi r^{2} \rho_{0}+\frac{2 r}{\pi} \int_{0}^{\infty} K\{a(K)-1\} \sin (K r) d K
$$

where, $\quad r$ : the distance from origin

$\rho_{0}:$ the average atomic density

$g(r)$ : the pair distribution function.

On calculating RDF from this equation, the value of $\rho_{0}$ was estimated from the extrapolation of the density data of molten $\mathrm{Fe}-\mathrm{Si}$ alloys measured by Gel'd $e t$ al., ${ }^{15}$ ) and $a(K)$ was extrapolated to $K=0$ smoothly by use of well-known thermodynamic relation $a(0)=\rho_{0} \chi_{\mathrm{T}} k T$, where $\chi_{\mathrm{T}}$, the isothermal compressibility, was taken from literature ${ }^{16)}$ for $\mathrm{Fe}$ and $\mathrm{Si}$, and estimated by assuming additive law for alloy specimens.

The number of atoms in the first coordination shell, i.e., coordination number $n_{1}$ was estimated by inte-

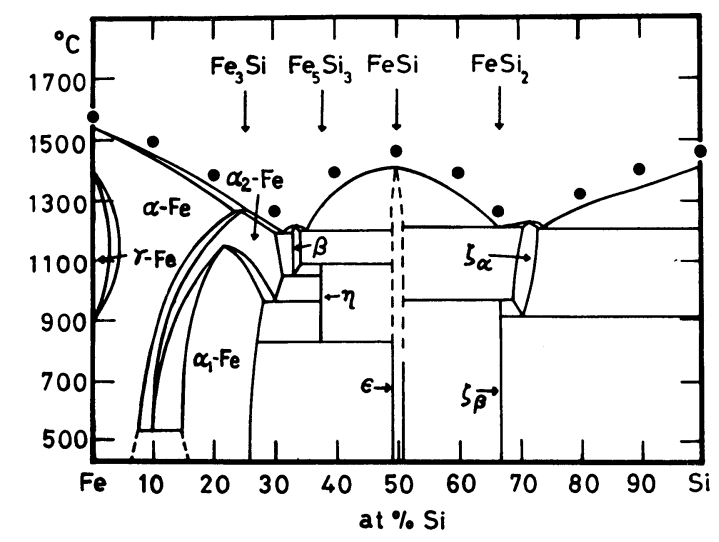

: the composition of specimens and their temperatures at which measurements were made

$\rightarrow$ : refer to solid compounds

Fig. 1. The phase diagram of Fe-Si alloy system.

grating RDF :

$$
n_{1}=\int_{r_{0}}^{r_{m}} 4 \pi r^{2} \rho_{0} g(r) d r
$$

where, $r_{0}$ : the limit below which $g(r)$ is zero

$r_{\mathrm{m}}$ : the value of $r$ at which RDF has first minimum on the higher $r$ side of the first peak.

Numerical calculation was carried out in Computation Center, Osaka University.

\section{Results and Discussion}

The total interference functions $a(K)$ of molten $\mathrm{Fe}-$ $\mathrm{Si}$ alloys obtained by use of Eq. (1) are shown for various compositions in Fig. 2, where the compositions of alloys and the temperatures of measurements are numerically indicated. The variation of the first peak position $K_{1}$ of $a(K)$ with composition is given in Fig. 3 which contains, for comparison, the results of Vatolin and Pastuhov ${ }^{2)}$ given as the first peak positions of the intensity curves at about $30^{\circ} \mathrm{C}$ above the liquidus, and those of Waseda et al. obtained for molten $\mathrm{Fe}$ and $\mathrm{Fe}-1,5,10 \mathrm{wt} \% \mathrm{Si}$ alloys at $1600^{\circ} \mathrm{C}^{17)}$ and for molten $\mathrm{Si}$ at $1460^{\circ} \mathrm{C}$. ${ }^{18)}$ The height $a\left(K_{1}\right)$ and the half width $W$ of the first peak of $a(K)$ are also indicated in Fig. 3. $a(K)$ of molten Fe shows a sharp, almost symmetric first peak at $2.99 \AA^{-1}$, which agrees with the results by other investigators. ${ }^{2,17)}$ For molten $\mathrm{Si}, a(K)$ shows an asymmetric first peak at $2.70 \AA^{-1}$ with its shoulder at $3.40 \AA^{-1}$, which is in agreement with the results of previous works. ${ }^{2,18)}$ As can be seen from Figs. 2 and 3, for the alloys in the concentration range of 10 to $40 \mathrm{at} \% \mathrm{Si}$, the overall feature of $a(K)$ as well as the first peak position $K_{1}$, the height $a\left(K_{1}\right)$ and the half width $W$ is almost similar to those of molten Fe. Since $a(K)$ in lower $\mathrm{Si}$ concentration range shows the contribution of $\mathrm{Fe}-\mathrm{Fe}$ correlation predominantly, these facts indicate that $\mathrm{Fe}-\mathrm{Fe}$ correlation like that in molten pure $\mathrm{Fe}$ still remains up to $40 \mathrm{at} \% \mathrm{Si}$ in molten $\mathrm{Fe}-\mathrm{Si}$ alloys. On the other side, for the alloys in the range of 50 to $80 \mathrm{at} \% \mathrm{Si}$, with increasing $\mathrm{Si}$ content, the shape of the first peak of $a(K)$ becomes broader and more asymmetric, its 


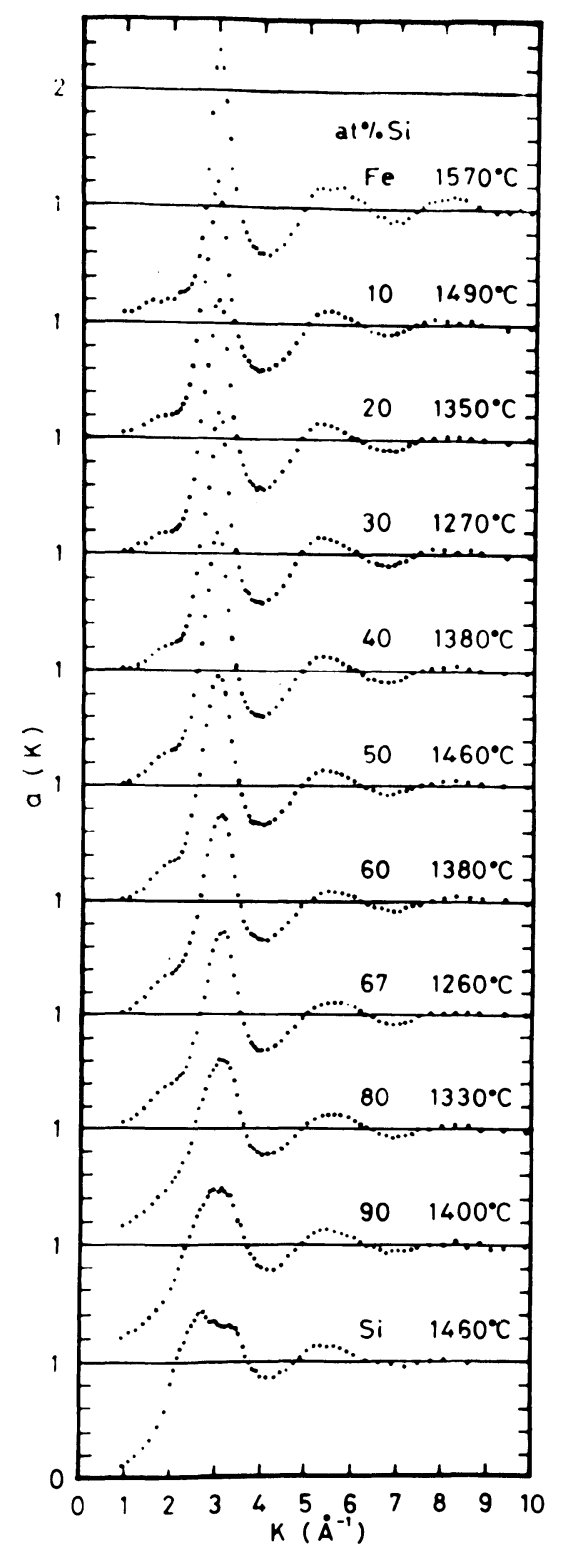

Fig. 2. Total interference functions $a(K)$ for molten $\mathrm{Fe}-\mathrm{Si}$ alloys at temperatures about $50^{\circ} \mathrm{C}$ above the liquidus.

position $K_{1}$ is shifted toward the higher $K$ side, the height $a\left(K_{1}\right)$ decreases and the half width $W$ increases in a manner consistent with a more open liquid structure. Finally at 90 at $\% \mathrm{Si}$, a shoulder, characteristic of molten $\mathrm{Si}$, comes to appear on the higher $K$ side of the first peak. As is evident from Fig. 3, it should be pointed out that the first peak positions of $a(K)$ obtained in the present experiment, $3.02 \AA^{-1}$ for 50 at $\%$ $\mathrm{Si}$ and $3.11 \AA^{-1}$ for $67 \mathrm{at} \% \mathrm{Si}$, show remarkable difference from those obtained by Vatolin and Pastuhov, ${ }^{2)} 3.10$ and $3.30 \AA^{-1}$ respectively, which were considered by them to correspond precisely to the positions of the diffraction lines from solid phases of $\varepsilon-\mathrm{FeSi}$ and $\zeta_{\alpha}-\mathrm{FeSi}_{2}$.

The total pair distribution functions $g(r)$ obtained by Eq. (3) are shown in Fig. 4 . The first peak position $r_{1}$ of RDF, i.e., the nearest neighbour distance, and the coordination number $n_{1}$ are given in Fig. 5 together with the previous data., ${ }^{2,417,18)}$ The nearest

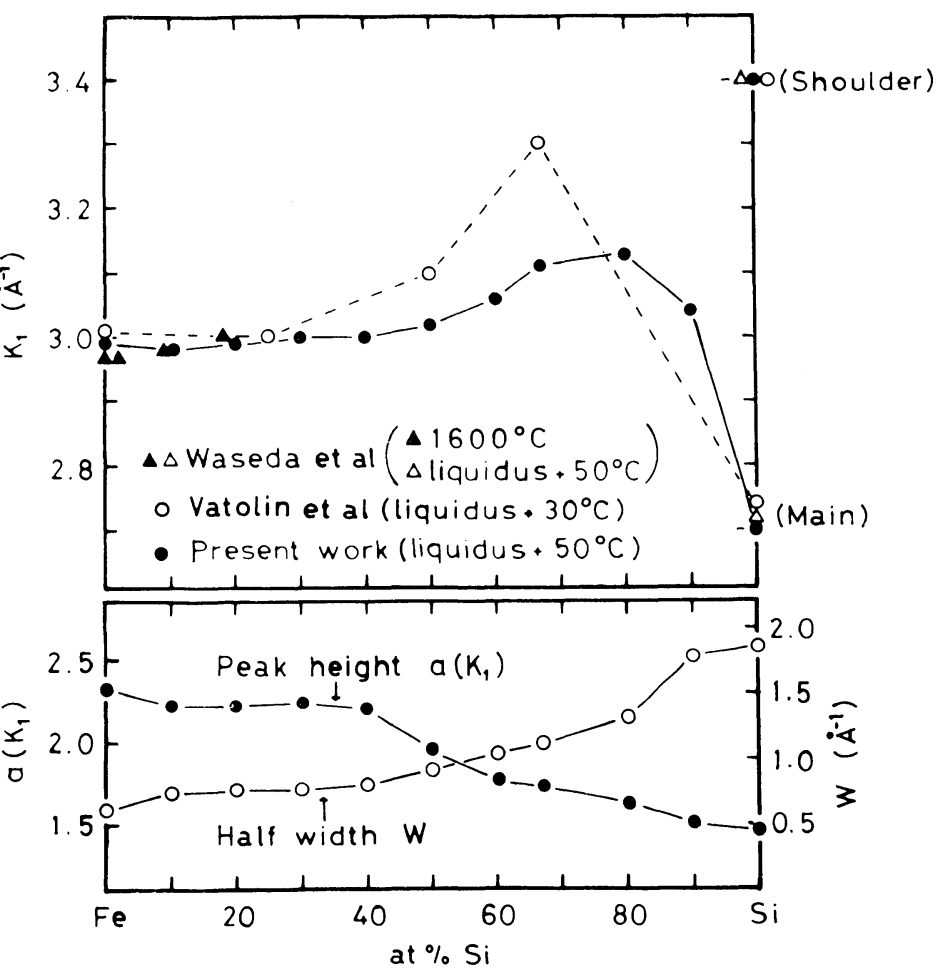

Fig. 3. Composition dependency of the position $K_{1}$, the height $a\left(K_{1}\right)$ and the half width $W$ of the first peak of $a(K)$ for molten $\mathrm{Fe}-\mathrm{Si}$ alloys.

neighbour distances $r_{1}$ for molten $\mathrm{Fe}$ and $\mathrm{Si}$ are found to be 2.55 and $2.53 \AA$ respectively, which agree fairly well with the results by previous investigators ${ }^{2,4,17,18)}$ except the case for molten $\mathrm{Si}$ by Vatolin and Pastuhov ${ }^{2)}(2.47 \AA)$. It can be seen from Figs. 4 and 5 that, for the alloys in the range up to 40 at $\%$ $\mathrm{Si}$, the pair distribution functions $g(r)$ have prominent first peaks and successive well-defined maxima. Besides, the nearest neighbour distance $r_{1}(2.55 \sim 2.58 \AA)$ and the coordination number $n_{1}(11.3 \sim 11.7)$ are nearly invariant from those of molten $\mathrm{Fe}(2.55 \AA$ and 11.2, respectively), thus indicating that molten $\mathrm{Fe}-$ Si alloys in the range up to $40 \mathrm{at} \% \mathrm{Si}$ have a nearly close-packed structure like that of molten Fe. For the alloys with concentration beyond 50 at $\% \mathrm{Si}$, with increasing Si content, the width of the first peak of $g(r)$ becomes narrower and the subsequent peaks are more strongly damped, and the coordination number $n_{1}$ decreases rapidly from 10.6 for 50 at $\% \mathrm{Si}$ to 6.5 for pure Si. These facts suggest that there appears the more open structure like that of molten Si with increasing $\mathrm{Si}$ concentration. The nearest neighbour distance $r_{1}$ decreases with $\mathrm{Si}$ content from $2.55 \AA$ for 50 at $\% \mathrm{Si}$ to $2.48 \AA$ for 80 at $\% \mathrm{Si}$ which is smaller compared to that of molten $\mathrm{Si}(2.53 \AA)$.

These behaviours of both $a(K)$ and $g(r)$ mentioned above lead us to deduce that the structure of molten $\mathrm{Fe}-\mathrm{Si}$ alloy system is nearly close-packed like that of molten $\mathrm{Fe}$ in the range up to $40 \mathrm{at} \% \mathrm{Si}$, and gradually changes to be more open, lower-coordinated with increasing Si concentration.

From the above mentioned, it follows that the partial interference functions for molten $\mathrm{Fe}-\mathrm{Si}$ alloys may be independent of composition in the range up to 40 


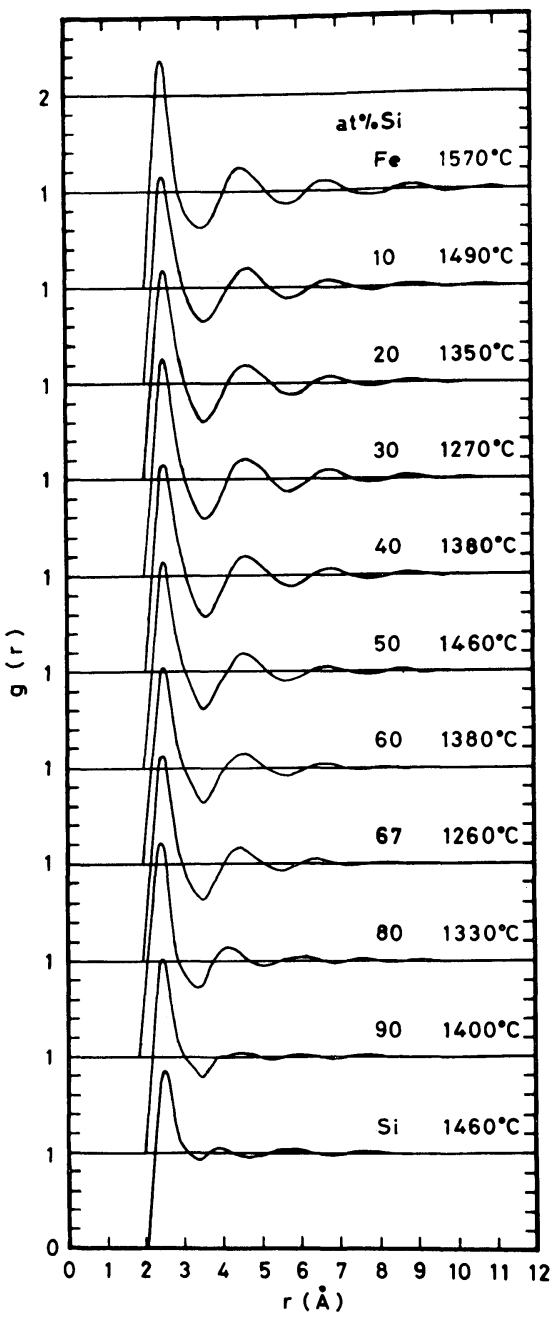

Fig. 4. Total pair distribution functions $g(r)$ for molten $\mathrm{Fe}-\mathrm{Si}$ alloys at temperatures about $50^{\circ} \mathrm{C}$ above the liquidus.

at $\% \mathrm{Si}$ where the nearly close-packing of atoms is maintained, while they may vary with composition in the range beyond $40 \mathrm{at} \%$ Si due to the appearance of the more open, lower-coordinated structure in Si-rich concentration range. These deduction may not agree with the previous conclusion that the partial structures are independent of the concentration in liquid Fe-Si. ${ }^{3)}$ Accordingly, it may not be correct to derive the partial interference functions for these alloys in the range beyond $40 \mathrm{at} \% \mathrm{Si}$ by a concentration method which necessarily involves the assumption that the three partial functions are independent of composition. Therefore, the partial interference functions $a_{\mathrm{FeFe}}(K)$ and $a_{\mathrm{FeSi}}(K)$ were evaluated by Eq. (2) only at the lower concentration of $\mathrm{Si}$, i.e., $30 \mathrm{at} \% \mathrm{Si}$, using $a(K)$ for 10, 30 and 50 at $\%$ Si alloys*, and shown in Fig. 6, where the vertical lines indicate the uncer-

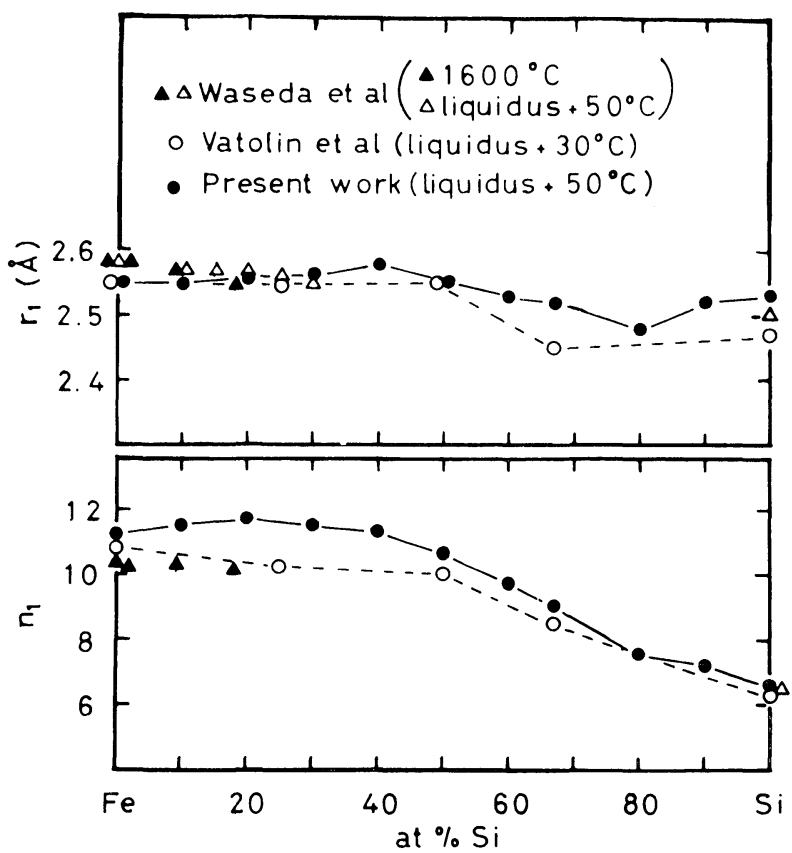

Fig. 5. Composition dependency of the nearest neighbour distance $r_{1}$ and the coordination number $n_{1}$ for molten $\mathrm{Fe}-\mathrm{Si}$ alloys.

tainty, an inevitable consequence of the experimental error. $a_{\mathrm{Sisi}}(K)$ obtained similarly has much more uncertainty than others in such a low $\mathrm{Si}$ concentration range since the atomic scattering factor of $\mathrm{Si}$ is about a half of that of $\mathrm{Fe}$; therefore, it was not shown in the figure. $a_{\mathrm{FeFe}}(K)$ and $a_{\mathrm{FeSi}}(K)$ calculated for the random mixture of hard spheres using PercusYevick equation, ${ }^{19)}$ together with $a(K)$ for molten $\mathrm{Fe}$ obtained from the experiment, were also shown in Fig. 6 for comparison. As can be seen from the figure, the overall feature of the first peak of $a_{\mathrm{FeFe}}(K)$ is in agreement with that of $a_{\mathrm{FeFe}}(K)$ obtained from P-Y calculation and also with that of $a(K)$ for molten Fe. The peak positions for three functions are found at $2.98,2.99$ and $2.99 \AA^{-1}$, respectively. On account of the uncertainty for $a_{\mathrm{FeSi}}(K)$ larger than for $a_{\mathrm{FeFe}}(K)$, the height of the first peak of $a_{\mathrm{Fesi}}(K)$ does not agree with those of $a_{\mathrm{FeSi}}(K)$ obtained from P-Y calculation. However, the first peak position of $a_{\mathrm{FeSi}}(K)$ at $3.05 \AA^{-1}$ agrees fairly well with that of $a_{\mathrm{FeSi}}(K)$ at $3.02 \AA^{-1}$ obtained from P-Y calculation. These facts encourage us to believe that the structure of molten $\mathrm{Fe}-\mathrm{Si}$ alloys in the range up to $40 \mathrm{at} \% \mathrm{Si}$ could be, to the first approximation, explained by the random mixture of hard spheres.

Some possible suggestions on the variation of the structure with composition for molten $\mathrm{Fe}-\mathrm{Si}$ alloy system can also be obtained from the concentration dependency of the physical or thermodynamic proper-

* On evaluating the partial interference functions for Fe-Si alloys, it is desirable to use three $a(K)$ 's, all being within the concentration range up to $40 \mathrm{at} \% \mathrm{Si}$. However, it is obvious from Eq. (2) that the use of three $a(K)$ 's at concentrations too close to one another leads to an extraordinarily large error in the resultant partial interference functions. According to the estimation of the error based on the determinant ${ }^{6)}$ of the weighting factor in Eq. (2), for example, the use of $a(K)$ 's at 10,30 and 50 at $\%$ Si gives the error in $a_{\mathrm{FeSi}}(K)$ increased by 16 times that of $a(K)$, while the use of $a(K)$ 's at 20,30 and 40 at $\%$ Si causes the larger error in $a_{\mathrm{FeSi}}(K)$ amounting to 60 times that of $a(K)$. Therefore, in order to have possible determination of the partial interference functions, we did use $a(K)$ 's at 10,30 and $50 \mathrm{at} \% \mathrm{Si}$ at the sacrifice of uncertainty derived from the fact that the partial interference functions at 50 at $\%$ Si may vary slightly from those up to 40 at $\% \mathrm{Si}$. 

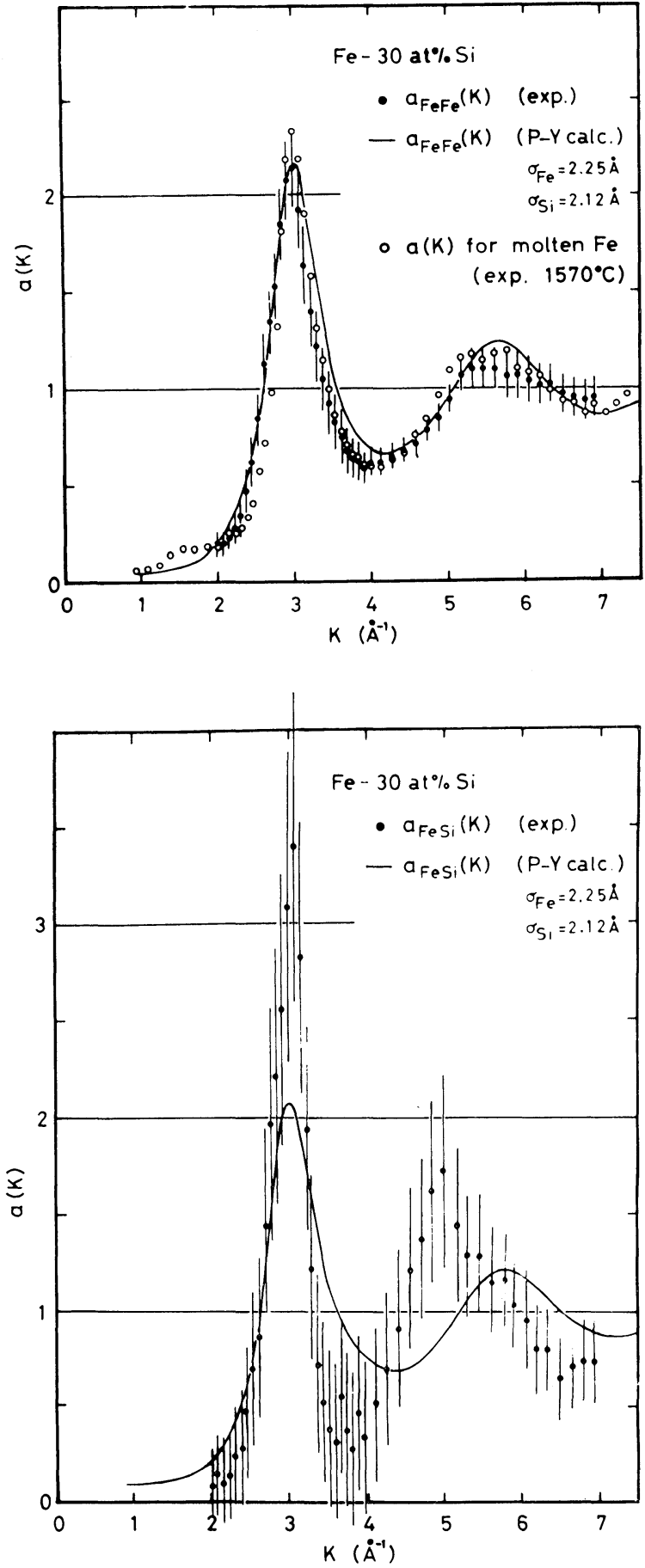

Fig. 6. Partial interference functions $a_{\mathrm{FeFe}}(K)$ and $a_{\mathrm{FeSi}}$ $(K)$ for molten $\mathrm{Fe}-30 \mathrm{at} \% \mathrm{Si}$ alloy evaluated from $a(K)$ for $\mathrm{Fe}-10,30$ and $50 \mathrm{at} \% \mathrm{Si}$ alloys by a concentration method and those calculated from $\mathrm{P}-\mathrm{Y}$ equation for the random mixture of hard spheres, together with $a(K)$ for molten Fe obtained by the experiment. Vertical lines indicate the uncertainty.

ties which are closely related to the liquid structure. For example, the molar volume ${ }^{20}$ and the excess stability $^{21)}$ for molten $\mathrm{Fe}-\mathrm{Si}$ alloys are shown in Fig. 7. As can be seen in the figure, the molar volume $V_{\mathrm{m}}$ increases with $\mathrm{Si}$ content gradually up to $50 \mathrm{at} \% \mathrm{Si}$, and then rapidly in the range beyond 50 at $\%$ Si. The partial molar volume of $\mathrm{Fe}, \bar{V}_{\mathrm{Fe}}$ decreases, and that of $\mathrm{Si}, \bar{V}_{\mathrm{Si}}$ increases abruptly at 50 at $\%$ Si. These

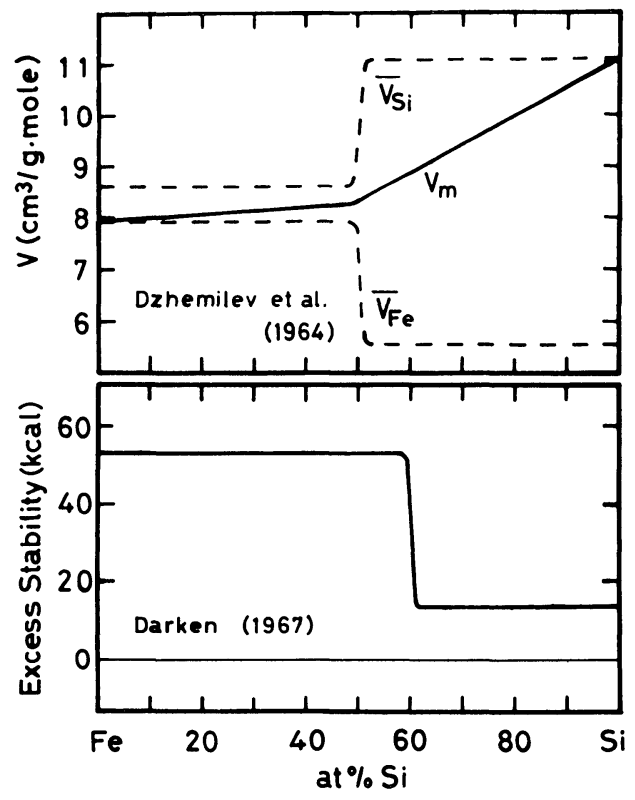

Fig. 7. Composition dependency of the molar volume $V_{\mathrm{m}}$, the partial molar volumes of $\mathrm{Fe}$ and $\mathrm{Si}\left(\bar{V}_{\mathrm{Fe}}, \bar{V}_{\mathrm{Si}}\right)$ and the excess stability for molten Fe-Si alloys.

facts suggest that the more open, lower-coordinated structure may appear and its influence gradually increases with $\mathrm{Si}$ content in the range beyond $50 \mathrm{at} \%$ Si. The excess stability, which represents thermodynamic stability of solution with reference to ideal solution, decreases abruptly at 60 at $\% \mathrm{Si}$. This fact also indicates that the more open, lower-coordinated structure may occur in the Si-rich concentration range.

Our deduction on the structure of molten $\mathrm{Fe}-\mathrm{Si}$ alloy system derived from the X-ray diffraction study, corresponds well and does not conflict with suggestions given by the variation of these properties with composition.

\section{Conclusions}

Detailed analysis of X-ray diffraction has been carried out on molten $\mathrm{Fe}-\mathrm{Si}$ alloy which is one of the fundamental systems in iron and steelmaking. The total interference functions $a(K)$ and the radial distribution functions $4 \pi r^{2} \rho_{0} g(r)$ were determined from intensity patterns obtained for molten $\mathrm{Fe}-\mathrm{Si}$ alloys over the whole concentration range at about 10 at $\%$ $\mathrm{Si}$ intervals at temperatures about $50^{\circ} \mathrm{C}$ above the liquidus.

(1) In the concentration range up to $40 \mathrm{at} \% \mathrm{Si}$ in molten $\mathrm{Fe}-\mathrm{Si}$ alloy system, the overall feature of $a(K)$ and $g(r)$, and the short range order parameters are almost similar to those of molten $\mathrm{Fe}$ and nearly invariant with composition. While, for the alloys in the range beyond 50 at $\% \mathrm{Si}$, the overall feature of $a(K)$ and $g(r)$, and the short range order parameters vary with increasing $\mathrm{Si}$ concentration.

(2) From these behaviours of $a(K)$ and $g(r)$, it is deduced that the structure of molten Fe-Si alloys is nearly close-packed like that of molten $\mathrm{Fe}$ in the range up to 40 at $\% \mathrm{Si}$, and then gradually changes to be more open, lower-coordinated with increasing 
Si concentration.

(3) The partial interference functions $a_{\mathrm{FeFe}}(K)$ and $a_{\mathrm{FeSi}}(K)$ of molten $\mathrm{Fe}-30$ at $\%$ Si alloy obtained from the experiment agree with those obtained from Percus-Yevick calculation, suggesting that the structure of molten $\mathrm{Fe}-\mathrm{Si}$ alloys in $\mathrm{Fe}$-rich concentration range can be explained, as the first approximation, by the random mixture of hard spheres.

(4) These deductions on the structure of molten $\mathrm{Fe}-\mathrm{Si}$ alloys correspond well with composition dependency of the molar volume and the excess stability.

\section{Acknowledgements}

The authors wish to express their appreciation to Prof. H. Endo, Department of Physics, Kyoto University, for valuable discussion and comments.

\section{REFERENCES}

1) R. Hultgren, P. D. Desai, D. T. Hawkins, M. Gleiser and K. K. Kelley: Selected Values of the Thermodynamic Properties of Binary Alloys, Metals Park, Ohio, (1973), 871.

2) N. A. Vatolin and E. A. Pastuhov: Spec. Rep. No. 19 The Forth Japan-USSR Joint Symposium on Physical Chemistry of Metallurgical Processes, ISIJ, Tokyo, (1973), 1.

3) Y. Waseda and S. Tamaki: Commun. Phys., 1 (1976), 3.

4) Y. Waseda and Y. Shiraishi: Tetsu-to-Hagané, 63 (1977), 1476.
5) Y. Kita, M. Ueda, Z. Morita, K. Tsuji and H. Endo: Liquid Metals, 1976, Conference Series; No. 30 (Proceedings of the 3rd Int'l Conf. on Liquid Metals, July, 1976), Inst. Physics, Bristol and London, (1977), 245.

6) Y. Waseda: The Structure of Non-crystalline Materials, McGraw-Hill Inc., New York, (1980), 27.

7) N. S. Gingrich: Rev. Mod. Phys., 15 (1943), 90.

8) J. Krogh-Moe: Acta Cryst., 9 (1956), 951.

9) N. Norman: Acta Cryst., 10 (1957), 370.

10) D. T. Gromer and J. T. Waber: Acta Cryst., 18 (1965), 104.

11) D. T. Gromer: Acta Cryst., 18 (1965), 17.

12) D. T. Cromer: J. Chem. Phys., 50 (1965), 4857.

13) H.H.M. Balyuzi: Acta Cryst., A31 (1975), 600.

14) S. I. Filippov, N. B. Kazakov and L. A. Pronin: Izv. VUZ av, Cher. Met., (1966), 8.

15) P. V. Gel'd, P. V. Kocherov, E. S. Levin and B. A. Baum: Fiziko Khimicheskie Osnovy Proizvodstva Stali, Nauka, Moskva, (1968), 9.

16) N. G. Halder and G.N.J. Wagner: J. Chem. Phys., 47 (1967), 4385.

17) Y. Waseda, M. Tokuda and M. Ohtani: Tetsu-to-Hagané, 61 (1975), 54.

18) Y. Waseda and K. Suzuki: Z. Physik, B20 (1975), 339

19) N. W. Ashcroft and D. G. Langreth: Phys. Rev., 156 (1967), 685.

20) N. K. Dzhemilev, S. I. Popel' and B. V. Tsarewsky: Fiz. Metal. Metalloved., 18 (1964), No. 1, 83; Translation: Phys. Met. Metallogr., 18 (1964), No. 1, 77.

21) L. S. Darken: Trans. Met. Soc. AIME, 239 (1967), 80. 